\title{
حوكمة الوحدات الصحية الريفية بمحافظة الفيوم
}

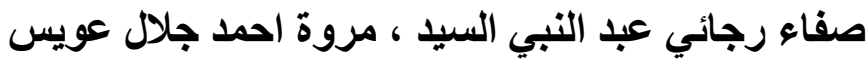

قسم الإقتصاد الزراعي- كلية الزراعة- جامعة الفيوم

Received: Aug. 10, 2018

Accepted: Aug. rq , 2018

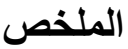

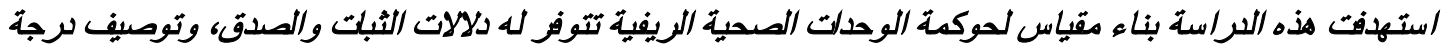

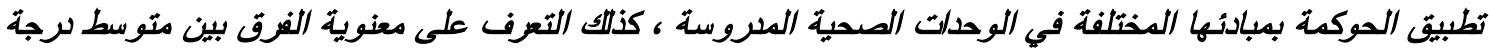

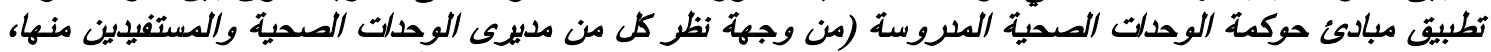

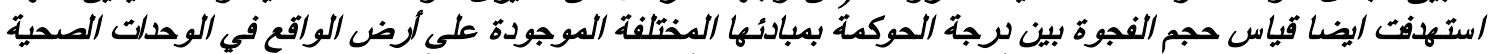

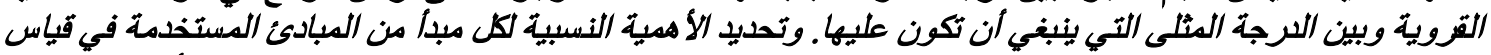

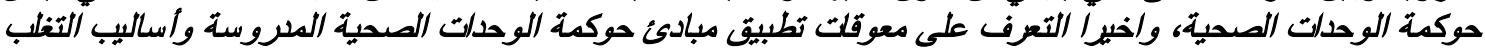
عليها.

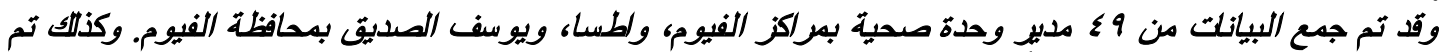

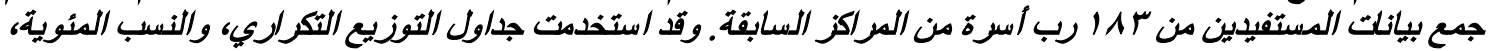

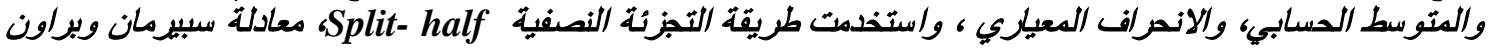
اللتوقع ، ومعامل جتمان، دعالل الثبات الفا (a) بطريقة كرونباخ، علاوة على إستخدم اختبار (T/test) وتحليل الانحدار

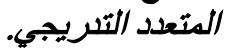

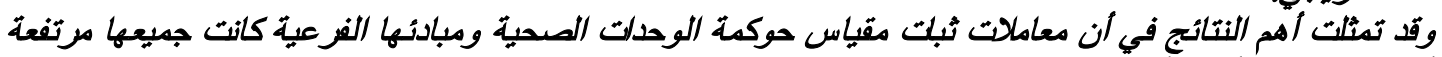

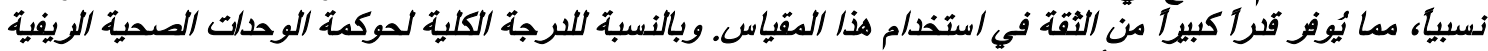

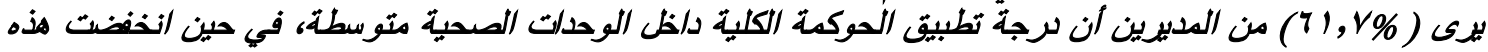

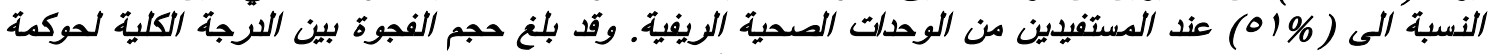

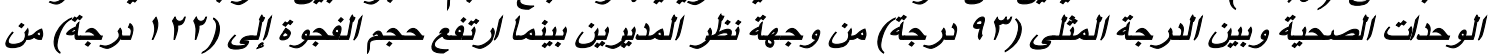

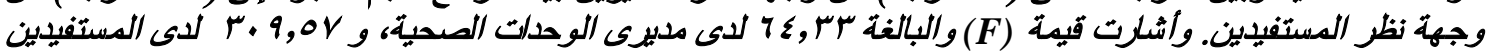

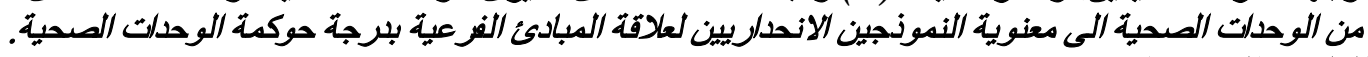

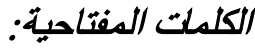

الصوكمةـ الوحدات الصحية الريفية_ الشفافيةـ المساءلة

الإفصاح سيساعد هذه المنظمات لتصبح مهيكلة على نحو أفضل، وأكثر شفافية، وبالتالي أكثر نجاحًا واستدامة.

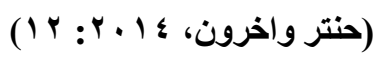

ويؤدي غياب المساولة وإنعدام الثفافية، وتفثي الفساد، وتدني الكفاءة والفاعلية وعدم الاستجابة للاحتياجات المختلفة للمواطنين، وعدم الالتزام بالقانون، وغير ذلتك من المظاهر التي تعكس غياب مبادئ الحوكمة إلى حرمان المواطن من حقوقه، وإنتهاك حقه في الحصول على الخدمات العامة بجودة عالية وبتكلفة مناسبة ويشكل عادل، ويؤدي إلى انخفاض مؤشرات التنمية البشرية المرتبطة بالفقر، والأمية والتذهور الصحي والبيئي، وهو ما يضعف في النهاية درجة الثقة
المقدمة والمشكلة البحثية تتميز الدول الناجحة بما فيها من هيئات ومؤسسات

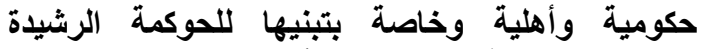

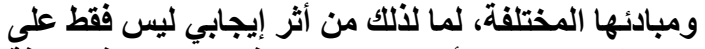

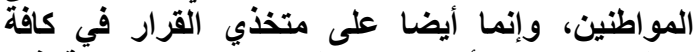

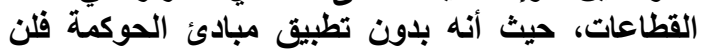
تصل منافع الذدمات بصورة كاملة وفعالة لكافة شرائح الئح المجتمع خاصة الفقراء وغير القادرين وستنتج فروقا وفا في

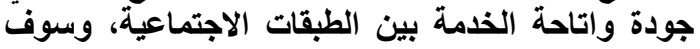

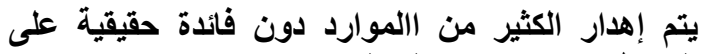

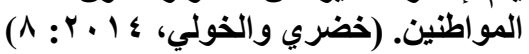
وعلى الرغم من حقيقة أن مفهوم حوكمة المؤسسات يرتبط ارتباطا وثيقا بالثركات والأسواق المالية فإن تطبيق هذا المفهوم في قطاع الرعاية الصحية له قيمة كبيرة. إذ تقدم حوكمة المؤسسات حلولا قابلة للتطبيق ويمكن أن تقلص العقبات التي تعترض المنظمات

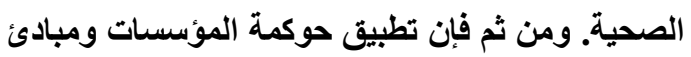


سلطات الإدارة الرشيدة ه. وقد تعددت التعريفات المقدمة لهذا المصطلح، وفيما يلي أهمها:

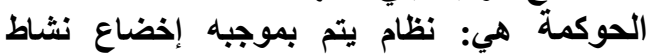

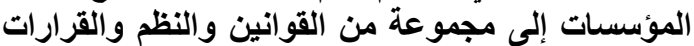

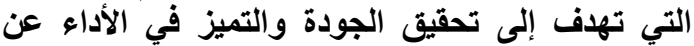

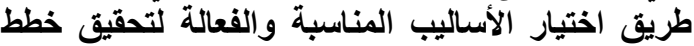
وأهداف المؤسسة وضبط الألعلاقات بين الأطراف الأساسية

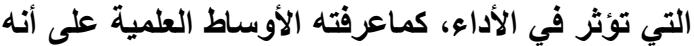

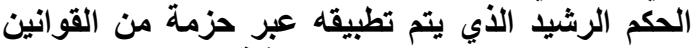
والقواعد التي تؤدي إلى الثنفافية وتطبيق القانون.

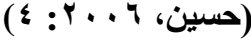

تعريف "منظمة التعاون الاقتصادي والتنمية"

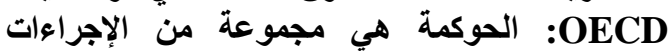
والعمليات التي يتم بموجبها إدارة المؤسسة ونئ والتحكم فيها

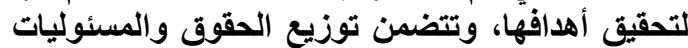

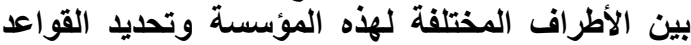

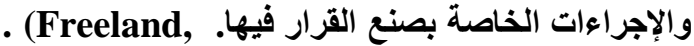

2007:74)

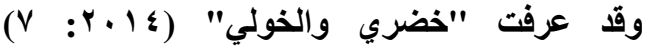

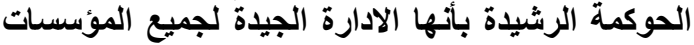

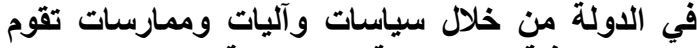

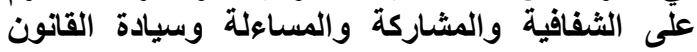

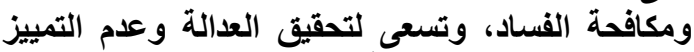

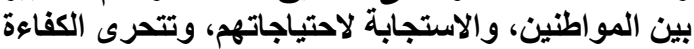

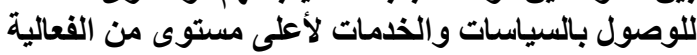
والجودة بما برضي المو اطنين.

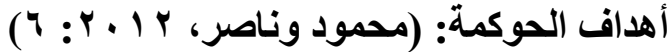

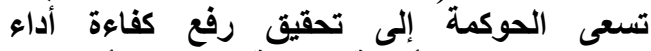
المؤسسات ووضع الأنظمة الكفيلة بتخفيف أو تقليل

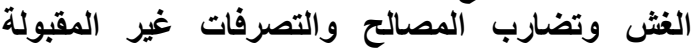

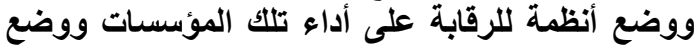

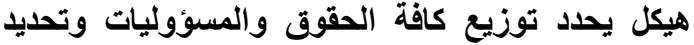

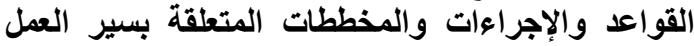

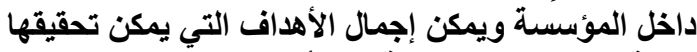
نتيجة تطبيق نظم الحوكمة بما يأتي : 1- تحقيق الثشفافية والعدالة ومنيح الحقي في مساعلة إدارة المؤسسة للجهات المعنية.

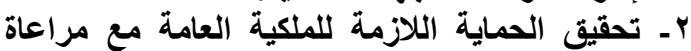
مصالح المتعاملين مع مؤسسات الدادية الدولة المختلفة والحد من استفلال السلطة في تفضيل المصلحة

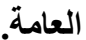

rـ تحقيق فرصة مراجعة الأداء من خارج أعضاء الإدارة التنفيذية تكون لهابة مهام واختصاصات وصنات وصلاحيات لتحقيق رقابة فعالة ومستقلة.

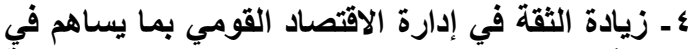

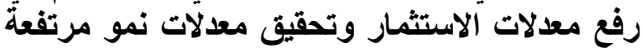

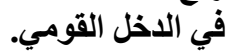

بين أفراد المجتمع وخاصة بين المواطنين والحكومة.

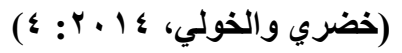

ويعد تبني مفهوم حوكمة القطاع الصحي بصفة عامة

والوحدات الصحية القروية بصفة خاصة، أمراً ضرورياً لمواجهة حالات الفساد الإداري الذي تعاني منه معظم هذه المنظمات الاجتماعية الهامة، ومن هنا تبلورت مشكلة هذه الدراسة في التعرف على درجة تطبيق مبادئ الحوكمة في الوحدات الصحية القروية بمحافظة الفيوم وما حجم الفجوة بين درجة الحوكمة الموجودة على أرض الواقع في الوحدات الصحية القروية وبين الارجة المثلى او المأمولة وكذلك التعرف على المعوقات التي تواجه تطبيق هذه المبادئ والحلول المقترحة لها حتى يتسنى النهوض بدور الوحدات الصحية في توفير الرعاية الصحية المناسبة لجميع المواطنين.

$$
\text { الأهداف البحثية: }
$$

ا ـ بناء مقياس لحوكمة الوحدات الصحية الريفية تتوفر

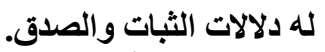

r- توصيف درجة تطبيق الحوكمة بمبادئها المختلفة

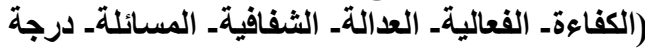

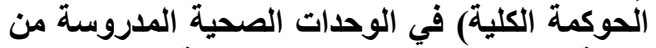
وجهة نظر مديرى الوحدات الصحية والمستفيدين الصينة

$$
\text { منها. }
$$

rـ التعرف على معنوية الفرق بين متوسط درجة تطبيق

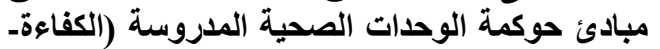

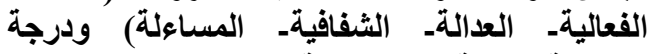
الحوكمة الكلية من وجهة نظر كل من مديرية الوحدات الصحية والمستفيدين منها. عـ قياس حجم الفجوة بين درجة الحوكمة بمبادئئها

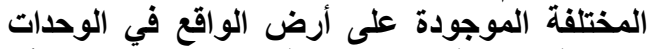
الصحية القروية وبين اللارجة المثلى التي ينبغي أن الن النيات تكون عليها. هـ تحديد الأهمية النسبية لكل مبأ من المبادئ المستخدمة في قياس حوكمة الوحدات الصحية الصية

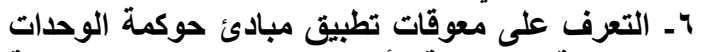

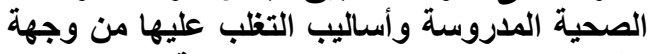
نظر كل من مديرى الوحدات الصحية والمستفيلين

$$
\text { منها. }
$$

$$
\text { الاستعر اض المرجعي }
$$

يعد مصطلح الحوكمة هو الترجمة المختصرة التي

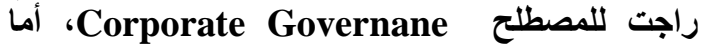
الترجمة العلمية التي اتفق عليها، فهي: 》أسلوب ممارسة 
تم استعراض مجموعة من الدراسات التي تناولت

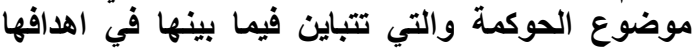
والمناهج التي استخدمتها كما يلي:

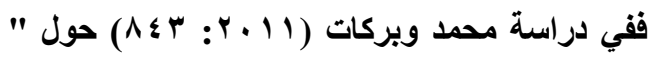
حوكمة المنظمات غير الحكومية " أوضحت النتائج أن

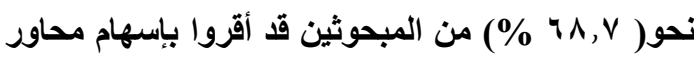
الحوكمة المدروسة، كما أمكن ترتيب محاور حوكمة جمعية تنمية المجتمع المحلي المدروسة ترتيبا تنازليا

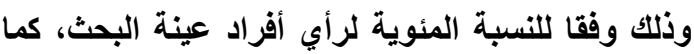
أوضحت النتائج أن الارجة الإجمالية لمحاور حوكمة جمعية تنمية المجتمع المحلي المدروسة كاتت ذات علاقة طردية ومعنوية عند مستوى معنوية (ه . , •)علي الأقل

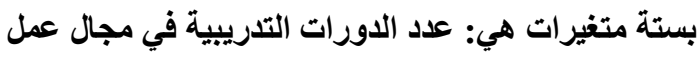

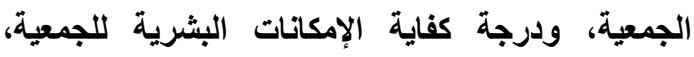
ودرجة كفاية الإمكانات التجهيزية للجمعية ، ودرجة كفاية الإمكانات المكانية للجمعية، ودرجة كفاية الإمكانات المالية للجمعية، وعدد سنوات العمل التطوعي بالجمعية،

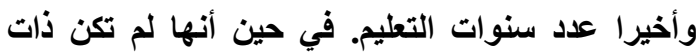
علاقة بمتغير السن، أيضا أثشارت النتائج إلي أن أن أنين المتغيرات المستقلة المدروسة مجتمعة تساهم في تفسير تباين الدرجة الإجمالية لحوكمة جمعية تنمية المجتمع

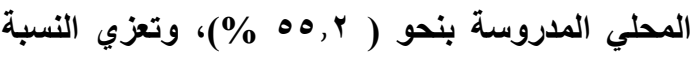
الباقية الي متغيرات أخري لم تضمنتها الدراسة. وفي دراسة "خضري وآخرون" (ع أب) والتي تبنت فكرة بناء مؤشرات لقياس الحوكمة الرشيدة واستخدامها في قياس وتقييم الحوكمة في ثلاث قطاعات اساسية تمس حياة المواطن وهي : التعليم الأساسي، والرعاية الصحية الأولية، والمياه والصرف الصحي. وقد تتضمن هذا المقياس تسع محاور أساسية هي: الثفافية والمشاركة والمساعلة وسيادة القانون ومكافحة الفساد، وتحقيق العدالة وعدم التمييز بين المواطنين، والاستجابة لاحتياجاتهم، والكفاءة للوصول بالسياسات والخدمات

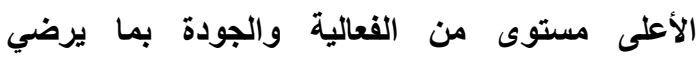

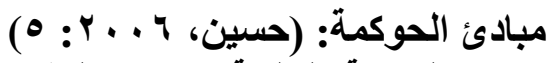

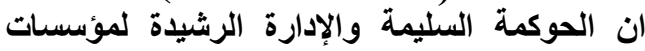

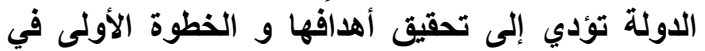

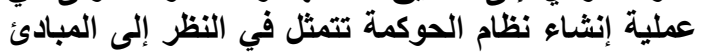
التي أعتمدتها منظمة التعاون والتنمية والتئي والتي وافقت

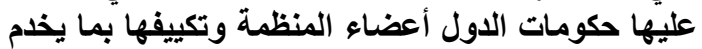
تحقق أهداف مؤسسات الدولة المختئل المختلة وكما يأتي:-

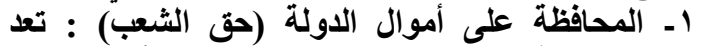
المحافظة على المال العام الهُف الهي الأول لجميع الأطراف ومن أهم السبل الكفيلة بتحقيق ذلكئل إكمال المظلة القانونية والتثريعية ويما يتلائم مع التغيرات التئية الحاصلة في البيئة الاقتصادية عمومائة والبئلة البئة الاقتصادية المحلية بوجه خاص.

r ـ ضمان حقوق المتعاملين مع مؤسسات الدولة :

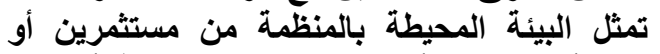

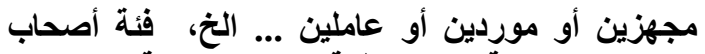

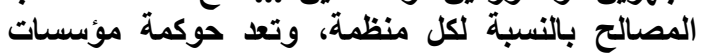

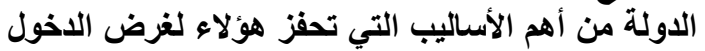

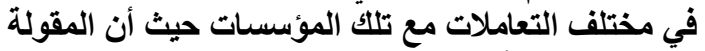

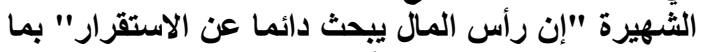

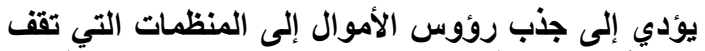

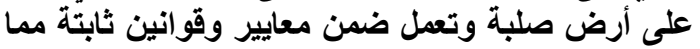
يشيع روح الاطمئنأن بالنسبة لكافة المتعاملين معها.

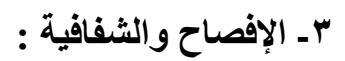

تعد مبادئ الإفصاح والثفافية والثفافية من أهم المبادئ

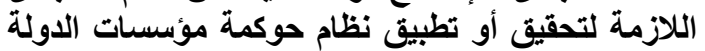
من خلال ضرورة توفر جميع المطلومات بدقة ولة ووضوح

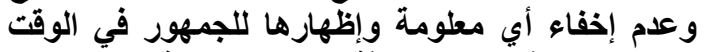

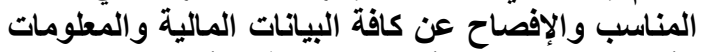
الأخرى وتقارير الأداء والملكية والكية وأسلوب استخات والمطام الصلاحيات وأن يتم الإفصاح عن الألمعلوماء والئة الآتية: أ أ. المبادئ المؤسسة.

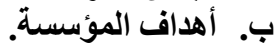
ج. الرواتب والمزايا الممنوحة إلى المدراء العامين. د. . المخاطر التي من المتوقع أن تحيط بعمل المؤسسة. و. البيانات المالَّة. و. و. المسائل المادية المتصلة بالعاملين. ز. . هياكل وسياسات الحوكمة المعتمدة.

$$
\text { ع - مهام وصلاحيات الإدارة : }
$$

يحدد نظام حوكمة مسؤوليات الإدادة الإة وسبل المتابعة

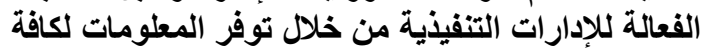
المستويات الإدارية ويذل العناية المهنية اللازمة ولئة ويما

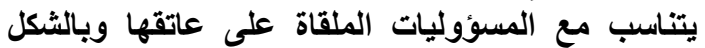

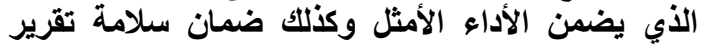
النشاط والتقاريز المالية والمحاسبية.

الار اسات السابقة 


$$
\text { فروض الاراسة: }
$$

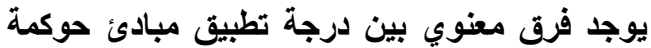

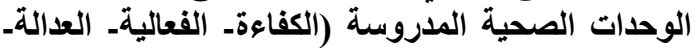

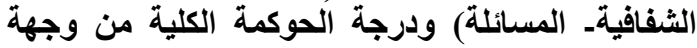

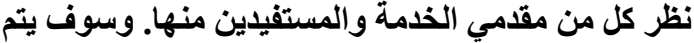
ختبار هذا الفرض في صورته الصفرية التالية:

" لايوجد فرق معنوي بين درجة تطبيق مبادئ حوكمة الوحدات الصحية التمدروسة (الكفاوة- الفعالية.

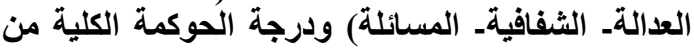
وجهة نظر كل من مقدمي الخدمة والمستفيدين منها".

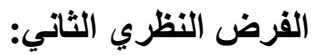

تتباين مبادئ الحوكمة الخمسة المدروسة (الكفاءةالفعاليةـ العدالةـ الثفافيةـ المساعلة) في درجة الاهمية النسبية داخل مقياس الحوكمة المستخدم، وسوف يختبر هذا الفرض في صورته الصفرية كما يلي: "تتساوي مبادئ الحوكمة الخمسة المدروسة فلية (الكفاءة_ الفعاليةـ العدالة_ الثفافيةـــ المساعلة) في درجة الاهمية النسبية داخل مقياس الحوكمة المستخدم"

$$
\text { أولاً: منطقة البّثي }
$$

تم إجراء الدراسة الحالية بمحافظة الفيوم، والتي تقع التع

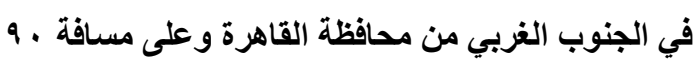
كم منها، وتنطوي محافظة الفيوم على ستة مراكز إداريـة هـ: الفيـوم، وسـنورس، وإبثـواي، و إطسـا، وطاميـة، ويوسف الصديق.

ونظـرا لصـعوبة دراسـة جميـع الوحـدات الصـحية

بمر اكز المحافظة الستة فقد تم اختيار ثلاثة مراكز بطريقة عمدية لاجراء هذه الدراسـة عليها وهي (الفيوم- اطســـ يوسف الصديق) وذلك للسببين التاليين: 1 ـ أن هذه المراكز هي الأعلى من حيث عدد الوحدات الصحية الريفية وذلك كما هو موضح بالجدول (1) الاعل من حئ عداد الوحدات r أن هـذه المراكـز تتبـاين بـين مـاهو متطـور (مركـز الفيوم)، ومـا هـو تقليدي (مركز اطسـا)، ومـا هـو لهو
المواطنين وقد أثارت النتائج إلى تقدم القطاع الخاص على القطاع الحكومي في مستوى تطبيق مبادئ الحوكمة حيث بلغ المؤشر العام للحوكمة في القطاع الخاص نحو ( • د درجة) في حين بلغ هذا المؤشر نحو (†, V؛ درجة)

$$
\text { في القطاع الحكومي. }
$$

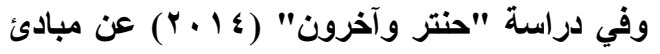

وقواعد الحوكمة في المستثفيات، حيث استهدفت الاراسة إعداد دليل لحوكمة المستثفيات يتضمن خمسة مبادئ أساسية هي: الحوكمة الاكلينيكية، ومجلس الادارة، والمراجعة والرقابة وادارة المخاطر، واستدامة ومسئولية المستشفى، الثفافية والافصاح وتمثلت أهم الهم نتائج تطبيق هذا الاليل بالنسبة للاطباء هناك افتقاد واضح للثقة بينهم وإدارة المستثفى بسبب وجود تعأرض مصالح واضح يثوب العلاقة بين الطرفين وبالنسبة لطاقم التمريض سلطت الأضواء على الحاجة إلى تدريب

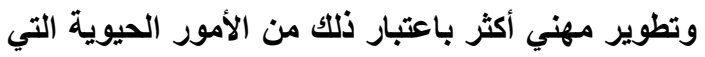
يجب على المستثفى الاضطلاع بها أما بالنسبة للعاملين الإداريين تهمل المستثفيات في الغالب هذا القطاع من حيث التدريب والتوجيه المهني في حين أنه بالنسبة للمرضى كاتت المطالبة بسياسات تمكنهم من المشاركة الفعالة في اتخاذ القرار بثأن خطة علاجهم وفي عمليات صناعة القرار داخل المستثفى.

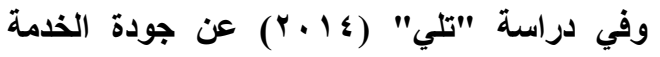
الصحية كمدخل لتحسين الحوكمة في المستثفيات، والتي استهدفت التعرف على دور جودة الخدمة الصحية بأبعادها المختلفة (الاعتمادية، الاستجابة، الأمان، التعاطف، الامكانيات المادية) في تحسين حوكمة المستثفيات بابعادها المختلفة (الثفافية، مجلس الادارة، ادارة المعلومات، لجأن التّقيق، ادارة المكافآت). وقد توصلت الدراسة إلى أن تطبيق مبادئ الحوكمة ينعكس بالايجاب على جودة الخدمة الصحية والعكس صحيح. 


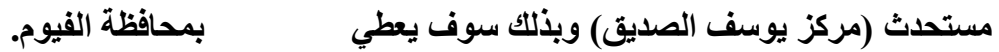

صورة شاملة عن حوكمة الوحدات الصحية الريفية جدول (1) ): عدد الوحدات الصحية الريفية بمر اكز محافظة الفيوم الثية

\begin{tabular}{|c|c|}
\hline عدد الوحدات الصحية الريفية & 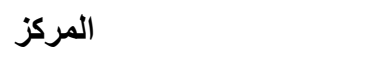 \\
\hline rr & الفيوم \\
\hline 10 & سنورس \\
\hline $1 \varepsilon$ & ابثواي \\
\hline rr & اطسا \\
\hline r & طامية \\
\hline rr & يوسف الصديق \\
\hline $1 \leqslant V$ & الاجمالي \\
\hline
\end{tabular}

المصدر: مركز المعلومات ودعم اتخاذ القرار بححافظة الفيوم، بيأنات غير منشورة، 17 بـ.

الصديق)، وقد بلغ اجمالي عدد الاسر المعيثية في القرى الترى

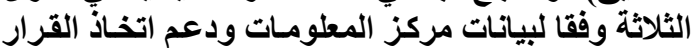

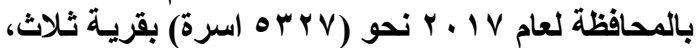

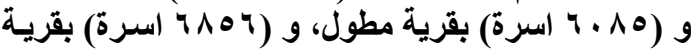

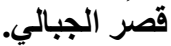
وللتعـرف علـي درجـة حوكمـة الوحـدات الصـــية

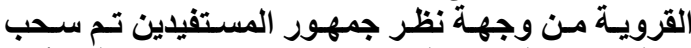

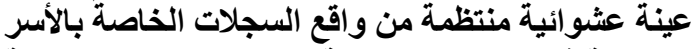

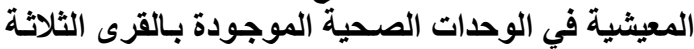

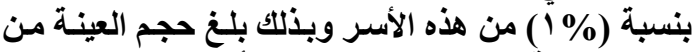

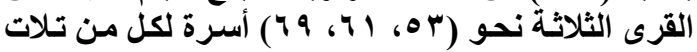

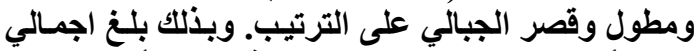

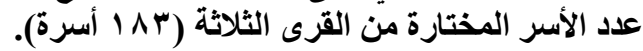

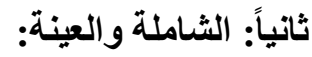

أ عينة الوحدات الصحية الريفية:

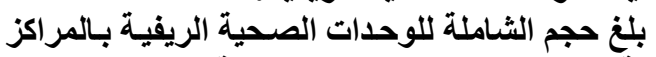

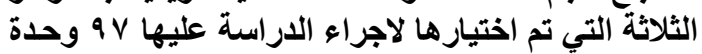

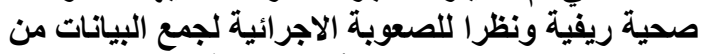

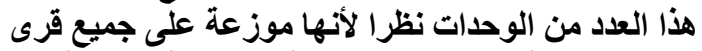

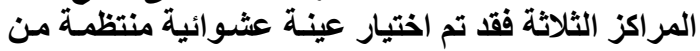

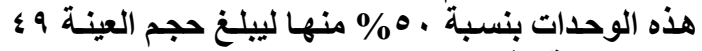

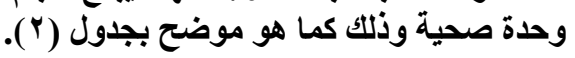

ب- عينة جمهور المستقيدين: ولاختيار عينة جمهور المستفيدين تم اختيّار وحدة

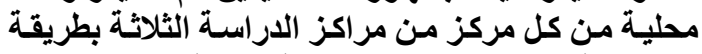

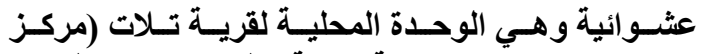

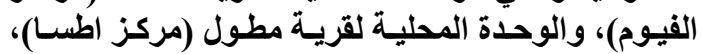

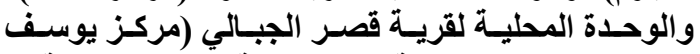

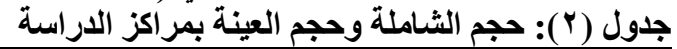

\begin{tabular}{|c|c|c|c|c|c|}
\hline \multicolumn{3}{|c|}{ عينة جمهور المستفيدين } & \multicolumn{3}{|c|}{ عينة الوحدات الصحية الريفية } \\
\hline العينة إ\% & الثـاملة (عدد الأسر) & القرى & العينة .0 \% & الشاملة & المركز \\
\hline or & OrYV & تلات & 17 & rr & الفيوم \\
\hline 71 & 7.10 & مطول & IV & $r r$ & اطسا (طا \\
\hline 79 & 7107 & قصر الجبالي & 17 & rr & يوسف الصديق \\
\hline IAr & 1АY & الاجمالي & $\leqslant 9$ & $9 \mathrm{~V}$ & الاجمالي \\
\hline
\end{tabular}


أ- بناءاً على ماتقدم من الاطار النظري والاراسات

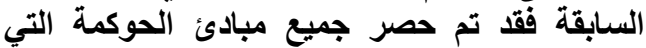

وردت في الاراسات السابقة وإعداد قائمة بها.

بـ تم عرض هذه القائمة على المجموعة البؤرية التي

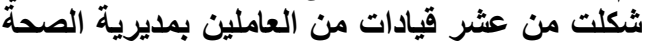

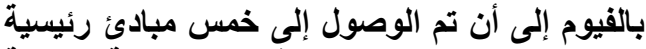
والتي تم الاتفاق عليها من قبل المبل المجموعة البؤرئة

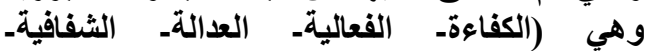
المساءلة).

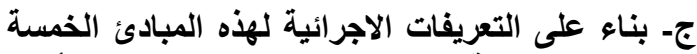

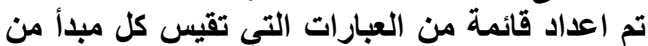
هذه المبادئ الخمسة المكونة المئة لمقياس حوكمة المئة

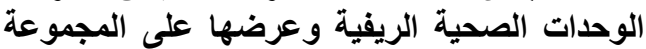

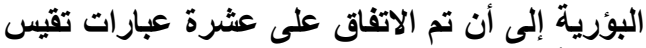

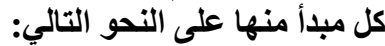

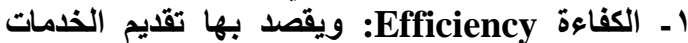
وتطبيق السياسات العامة بأقل تكلفة ممكنة وفي أقل وأل

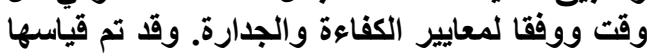
من خلال عشر عبارات هي: تثوفر دابلة داخل الوحدة

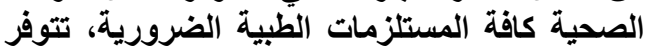

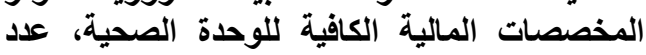
الأطباء الموجود كافي لتقديم الخدمة الصحية الجيدة

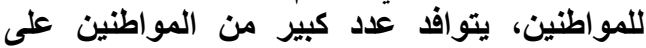

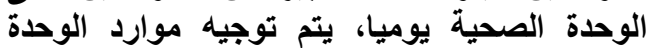
الصحية وتوظيفها بأقصى كفاءة، تتوفية الصور الأدوية في

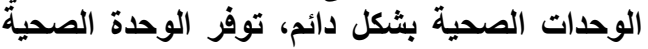
خدماتها في الوقت المناسب ويتكلفة وجودة ولمدة مناسبة،

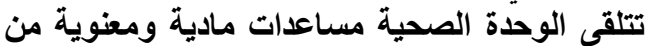

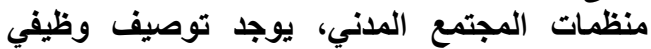
واضح لكل موظف داخل الوحدة الصحية، توجد خطة سنوية محدثة لتطعيم الاطفال داخل الوحدة الصحية.

r- الفعالية Effectiveness: ويقصد بها تحقيق الإنية الأهداف التي أنثئت الوحدة الصحية من أجلها. وقال

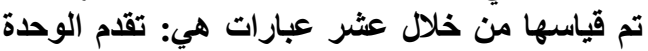

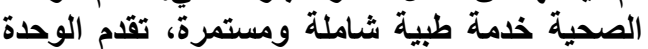

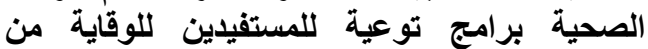
الأمراض المعدية وغير المعدية، تسعى الوحدة المائة الصحية لإنثاء نوادي الأسرة لنشر الثقافة الصحية

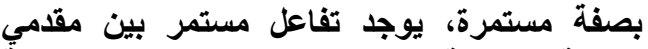

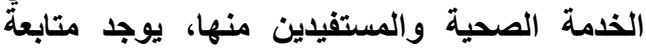

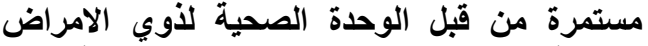

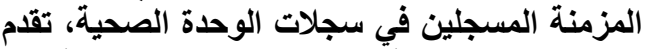

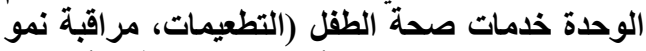

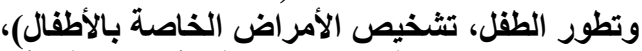
تقدم الوحدة الصحية خدمات صحة الأم (رعاية الأم الأم)

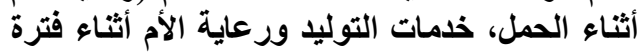

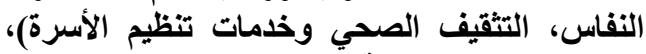

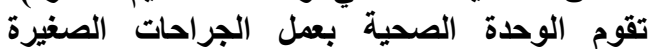
الطارئة، تسنطيع الوحدة الصحية اكتشاف وعلاج
ثالثاً: أدوات جمع البيانات:

لتحقيق اهداف الدراسة تم الاعتماد على أكثر من

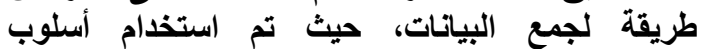
المجموعات البؤرية Focus Group لاعداد مقياس لحوكمة الوحدات الصحية الريفية تتوفر لله دلالات الثبات الثبات

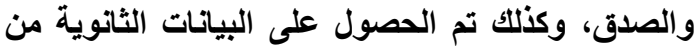
السجلات و والمنثورات الرسمية المولية الموجودة بمركز المعلومات ودعم اتخاذ القرار بمحافظة الفيوم. وللحصول التصول على البيانات الأولية فقد تم تصميم استمارتي إستبيان

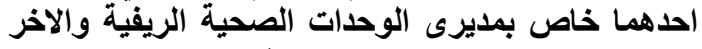

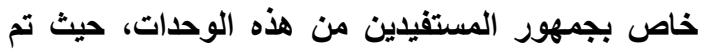
إجراء اختبار قبلي Pre- test لبنود الاستبيانان للتأكد

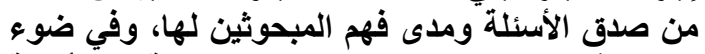

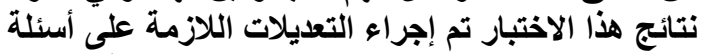

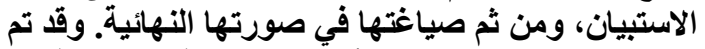

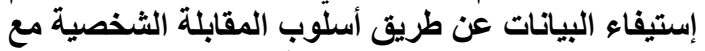

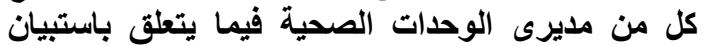

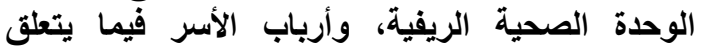

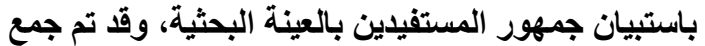
البيانات البحثية خلال شهري نوفمبر وديسمبر بالئرة لعام

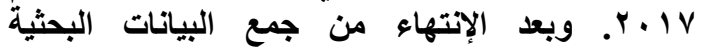

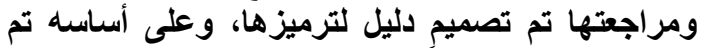

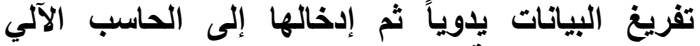

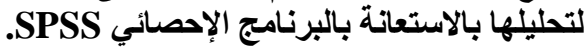

$$
\text { رابعاً: أدوات التحليل الإحصائي: }
$$

تم تحليل البيانات بالاستعانة بعدد من أساليب التحليل

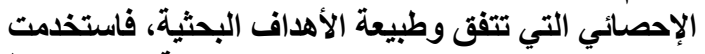

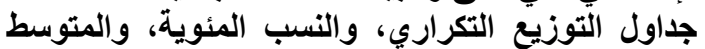

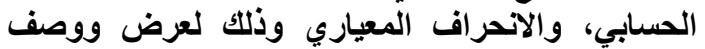

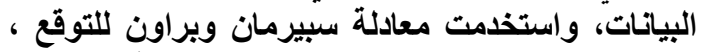

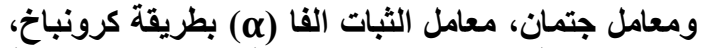
لقياس درجة ثبات مقياس حوكمة الوحدات الوبات الصحية

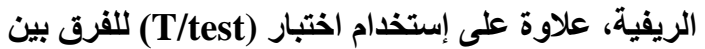
متوسطين للمقارنة بين متوسطي درجة المبنة حوكمة الوحدات

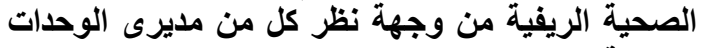

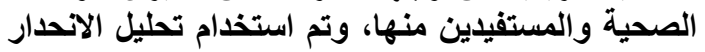

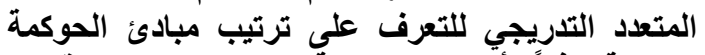

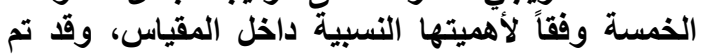

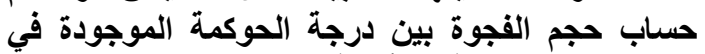

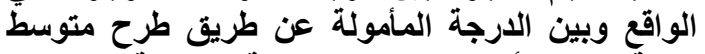

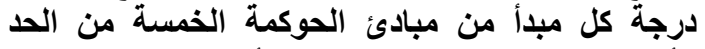
الأقصي للمقياس الخاص بكل مبادئ سواء سواء كان للنتائج الخاصة بمديرى الوحدات الصحية أو المستفيدين منها لأبها وكنلك الحال بالنسبة للارجة الكلية لحوكمة الوحدات الكيات الصحية الريفية. - اليال

خامساً: الخطوات الاجرائية لبناء مقياس لحوكمة

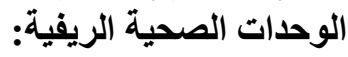


متعددة وفعالة للمراقبة والمساعلة. وقد تم قياسها من خلال عشر عبارات هي: توجد آليات لمساعلة الوحدات الصحية داخل وخارج القطاع الصحى، توجدات

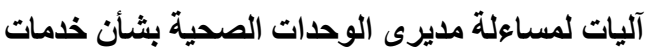
الرعاية الصحية، تتو افر الموارد والامكانيات اللازمة المانة

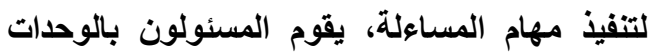

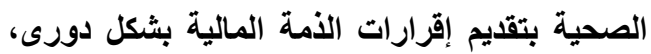
تتوافر قوانين ولوائح وقرارات منظمة للعمل فى فئه

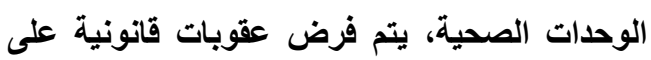
العاملين فى حالة خرق القوانين المنظمة للوحدات

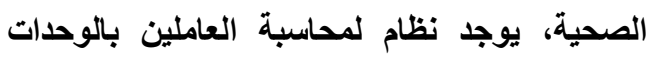

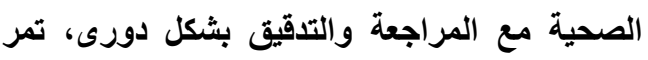

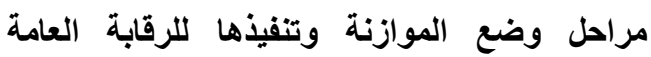

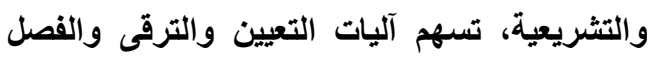
للعاملين فى الوحدات الصحية فى الحد من الفساد، التهات

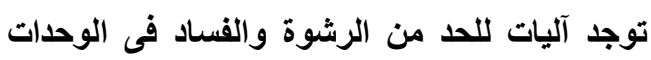

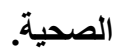

وكان مدير الوحدة الصحية و المستقيد منها يقوم

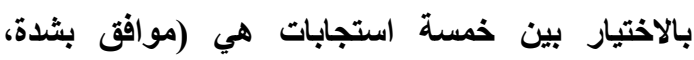

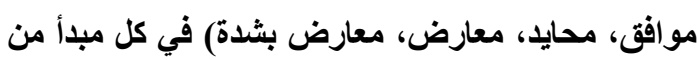

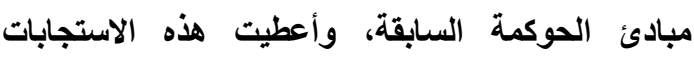

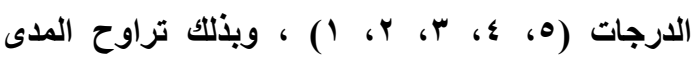
النظري لكل مبدا منهم بين(• (1- ، (0) درجة. צـ الدرجة الكلية لحوكمة الوحدات الصحية الريفية: وتم

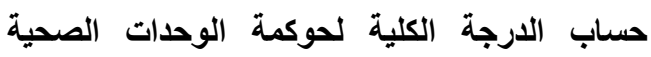

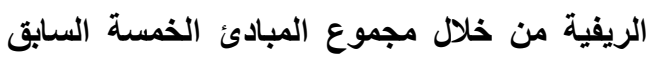
الاثارة اليها وبذلك اشتمل مقياس حوكمة الوحدات

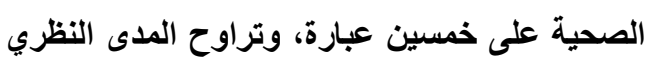

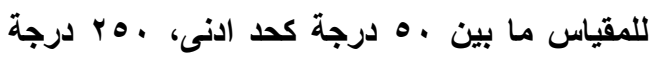
كد اقصى.

$$
\text { النتائج البحثية ومناقشتها: النها: }
$$

اولاً: النتائج الخاصة بإعداد مقياس كمي لحوكمة الرئها

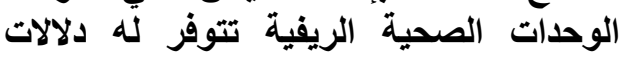

$$
\text { الثبات والصدق. الصية }
$$

اختص الهذف الأول للاراسة بيناء مقياس كمي

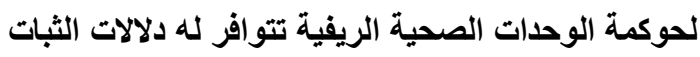

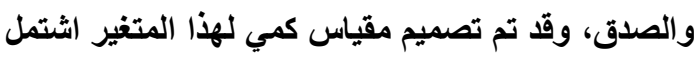

حالات قصور الدورة الدموية، تقدم الوحدة علاج

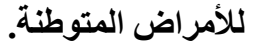

rـ العدالة Equity ويقصد بها تبني سياسات وقوانين العين وتضمن التعامل مع المواطنين على قلى قدم المساواة ودون تمييز وفقا للنوع النوع او الدين الين او الطبقة

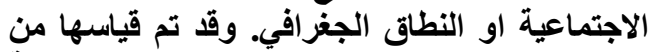

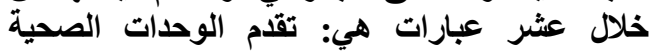

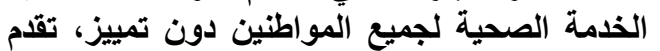

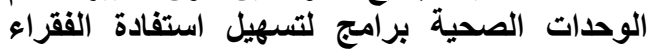

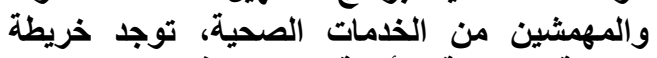
للرعاية الصحية الأولية توضح فيهات التهية تواحتياجات،

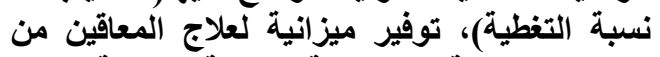

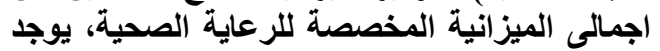
ميزانية لرعاية الأم والطفل من اجمالى الميلية الميزانية

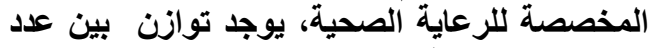

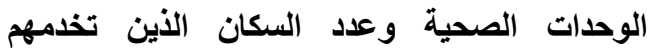

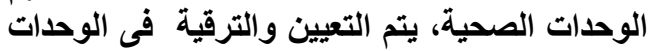

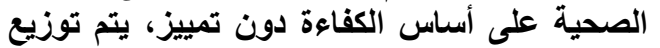

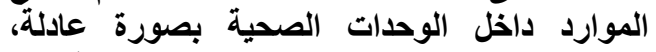

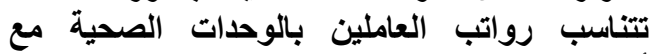
أقرانهم بالقطاع الخاص، تعطى امتيازات للعاملين العاتين بالوحدات الصحية فى المناطق النائية.

ع- الثفافية Transparency: ويقصد بها سهولة الحصول على المعلومات والانفتاح في العلاقة بين الوحدة الصحية والمواطنين. وقد تم قياسها من خلال عشر عبارات هي: توجد ألية واضحة لعملية اتخاذ القرارت داخل الوحدات الصحية، يوجد استجابه لطلبات الحصول على المعلومات من العاملين بالوحدات الصحية، يوجد توصيف وظيفى واضح لكل العاملين بالوحدات الصحية، يتم الاعلان عن القرارات الجديدة للموظفين بثكل دورى ودقيق، يتم اتاحة تقارير دورية عن أنثطة الوحدات الصحية، يتم

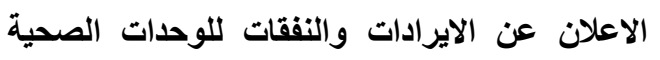

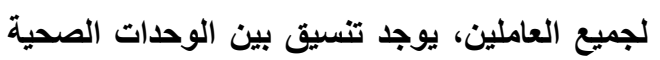

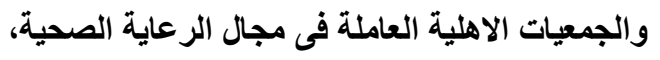
تقوم الوحدات الصحية بتوعية المواطنين بالقضايا

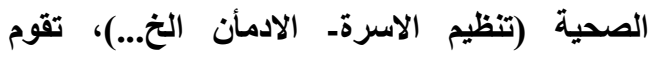

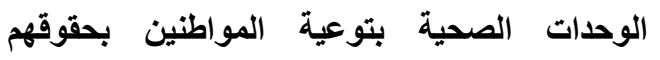
الصحية، تقوم الوحدات الصحية بتقديم تقارير دورية عن الأنشطة والخدمات التى تقوم بتقديمها. هـ المساولة Accountability: ويقصد بها تحمل الالتزامات، وتبعات المسؤوليات، وايجاد جهات وسبل ولئل 
بمديرى الوحدات الصحية وهي: معادلة سبيرمانبراون Spearman- Brown Formula، ومعادئة جتمان Guttman Formula، وطريقة كرونباخ Cronbach Method

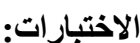

على خمسة مبادئ رئيسية هي: الكفاءة، الفعالية، العدالة، الثفافية، المساءلة. وفى ضوئ رئية ما توصلت إليه الاراسة يمكن استعراض النتائج الخاصة بهذا الهاءف فئف

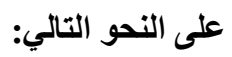
أـ النتائج الخاصة بثبات المقياس:

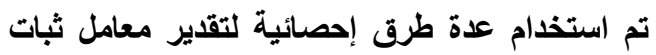

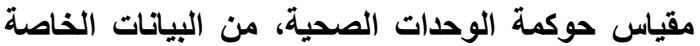
جدول (r) نتائج اختبارات ثبات مقياس حوكمة الوحدات الصحية باستخذام أربعة طرق احصائية مختلفة.

\begin{tabular}{|c|c|c|c|}
\hline \multicolumn{3}{|c|}{ معامل الثبات } & \multirow{2}{*}{ الوحبادئ حوكمة } \\
\hline طريقة كرونباخ & معادلة جتمان & سبيرمان- براون & \\
\hline ., $\vee$ १ & $\cdot, \mathrm{VN}$. &.,$V Y r$ & 1- الكفاءة \\
\hline 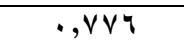 & . & $\cdot, \vee \vee \curlyvee q$ & r - الفعالية \\
\hline$\cdot, 9.9$ & . & $\cdot, \wedge \leqslant 1$ & بَ- العدالة \\
\hline., $91 Y$ & $\cdot, \wedge \backslash \leqslant$ & .,人04 & ـ- الثفافية \\
\hline$\cdot, 91 \leqslant$ & $\cdot, \wedge q \leqslant$ & . & هـ المساعلة \\
\hline -,9 $\leqslant 1$ & - & $\cdot, \vee \vee \leqslant 1$ & الصحيةس الكلي لحوكمة الوحدات \\
\hline
\end{tabular}

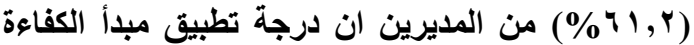

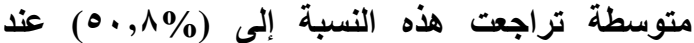
المستفيدين. وكانت النتيجة مماثلة في كل من من مبأئي

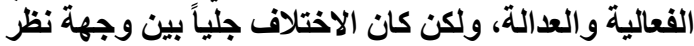
كل من المديرين والمستفيدين في مبأي الثابي الثفافية

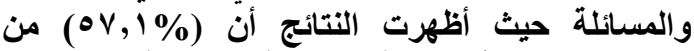

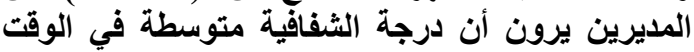

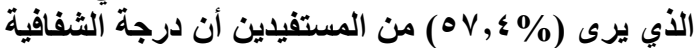

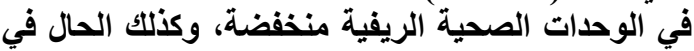
مبدأ المساعلة حيث يرى(

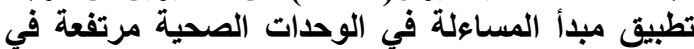

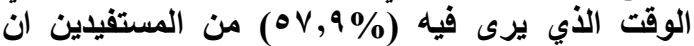
درجة تطبيق مبدأ المساعلة في الوحدات الصدية الصحية منخفضة، وبالنسبة للارجة الكلية لحوكمة الوحية الوحدات

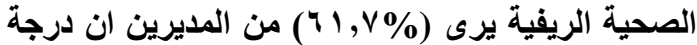

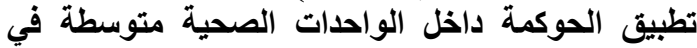
حين انخفضت هذه النسبة الى (1\% 10 (0) عند المستفيدين من الوحدات الصحية الريفية.

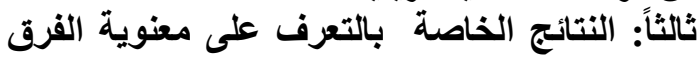
بين درجة تطبيق مبادئ حوكمة الوحدات الصحية المدروسة من وجهية مبادية نظر كل من الوحئ مديري الوحدات الصحية "مقدمي الخدمة نطية

$$
\text { والمستفيدين منها. }
$$

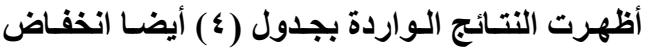

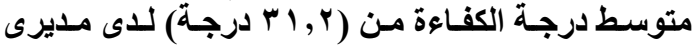

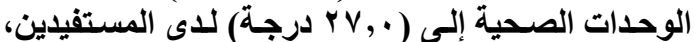

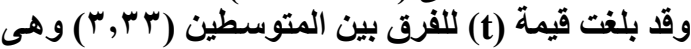

ويتضح من النتائج الواردة بالجدول أن معاملات ثبات كائ مقياس حوكمة الوحدات الصحية ومبادئئه الفرعية كاتئت جميعها مرتفعة نسبياً، مما يُوفر قدراً كبيراً من الثقة في الثياتي استخدام هذا المقياس نسبا،

بـ النتائج الخاصة بصدق المقياس: ـ الصدق الظاهري للمقياس (صدق المحكمين):

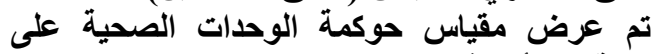

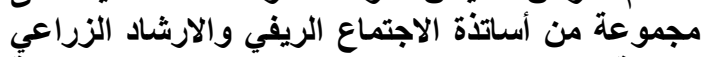

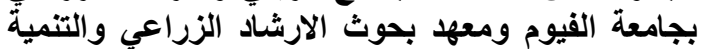

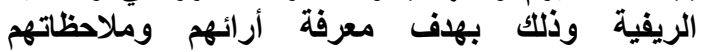

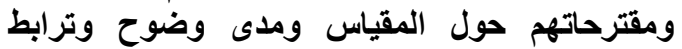

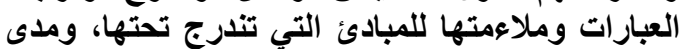

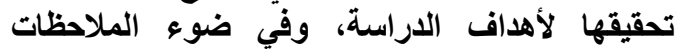

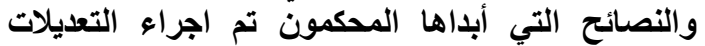

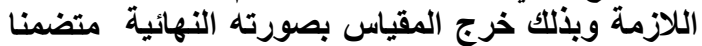
خمسة مبادئ أساسية للحوكمة، ويشتئمل كل مبدأ على التى

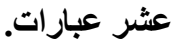

ثأنياً: النتائج الخاصة بتوصيف درجة تطبيق

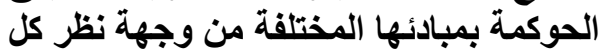
من مديرى الوحدات الصحية والمستقيدين

$$
\text { منها: من ملير }
$$

يتضح من البيانات الواردة بجدول (؛ ) أن هنالك تباين كبير بين وجهة نظر كل من مديرى الوحدات الوات الصحية

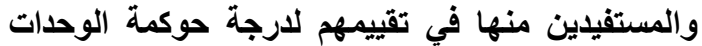
الصحية ومبادئها المختلفة، ففي الوقت الذي يركية الوحئ فيه 


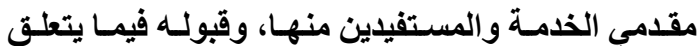

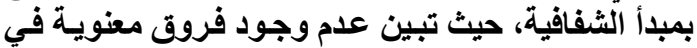

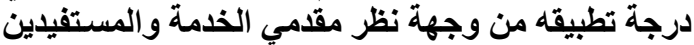
منها.

ويتضح من النتائج السابقة أن مديرى الوحدات

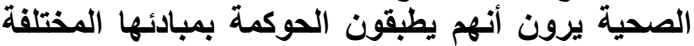

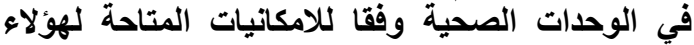

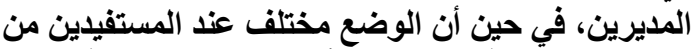
الوحدات الصحية فهم يرون أن الوحدين الوحدات الصحية ينبغي فئني

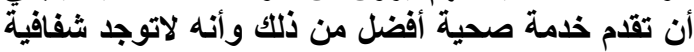

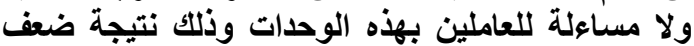
الرقابة وعدم توفر الامكانيات اللازمة لتمدين لتديم خدمة طبية

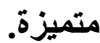

رابعاً: النتائج الخاصة بقياس حجم الفجوة بين درجة

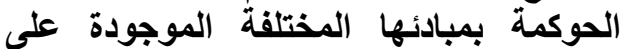

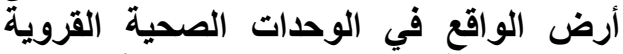
وبين الارجة المثلى التي التي ينبغي أن تكون

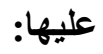
اوضحت النتائج الواردة بجدول (ع (ع) أن حجم الفجوة

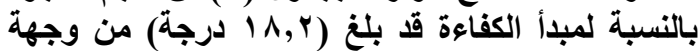

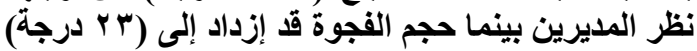

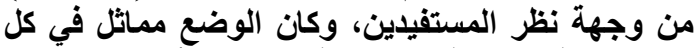

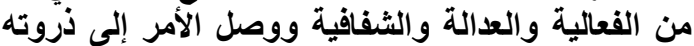

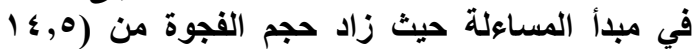

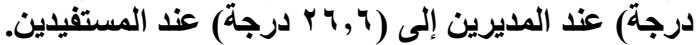

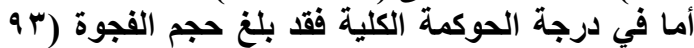
درجة) من وجهة نظر المديرين بينما ارتفع المجة حجم الفجوة

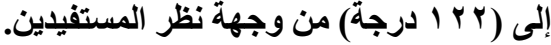

معنوية عند المستوى الاحتمـلي 1 ., ..، ممـا يعني وجود

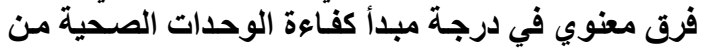

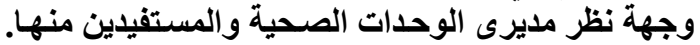

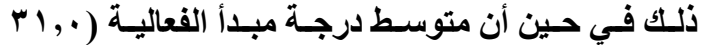

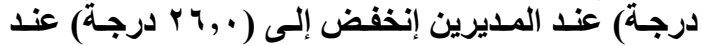

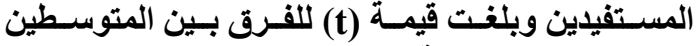

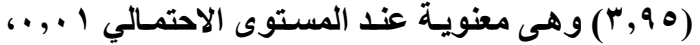

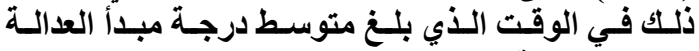

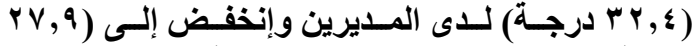

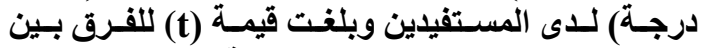

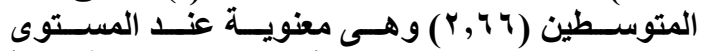

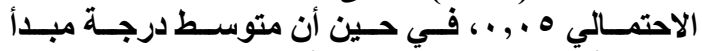

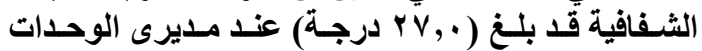

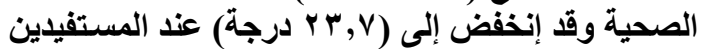

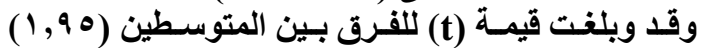

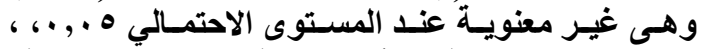

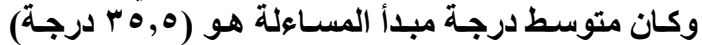

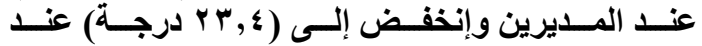

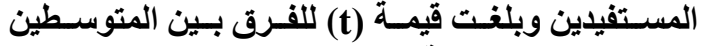

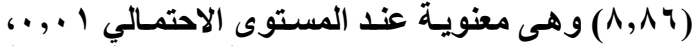

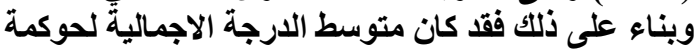

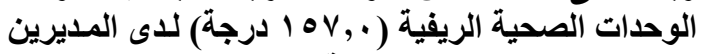

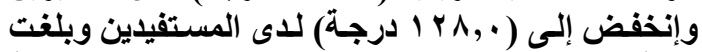

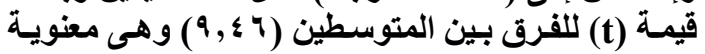

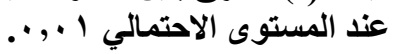

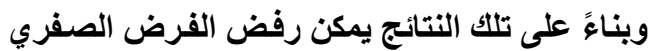

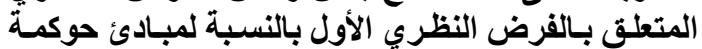

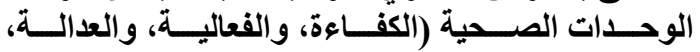

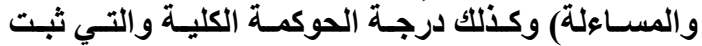

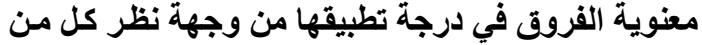
جدول (؛ ): درجة تطبيق الحوكمة بمبادئها المختلفة من وجهة نظر كل من مديرى الوحدات الصحية والمستفيدين منها

\begin{tabular}{|c|c|c|c|c|c|c|c|c|c|}
\hline \multirow[t]{2}{*}{ قيمة t } & \multicolumn{4}{|c|}{ المستفيدين من الوحدات الصحية } & \multicolumn{4}{|c|}{ مديرى الوحدات الصحية } & \multirow[b]{2}{*}{ الحوكمة ومبادئها المختلفة } \\
\hline & الفجوة & المعياري & المستوسط & $\%$ & الفجوة & المعياري & المستوسط & $\%$ & \\
\hline \multirow[t]{3}{*}{$* * r, r r$} & $r r,$. & $\mathrm{v}, \mathrm{v}$ & $r v$, & $r q, 7$ & $1 \wedge, r$ & $\neg, \mathrm{V}$ & $r_{1}, r$ & $r_{\cdot}, \varepsilon$ & ـ - منخفضة (اقل من ع r درجة) \\
\hline & & & & $\bullet,, \wedge$ & & & & $\$ 1, r$ & 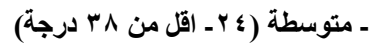 \\
\hline & & & & $1 r, 7$ & & & & $1 \wedge, \varepsilon$ & - مرتفعة (^^ درجة فأكثر) \\
\hline \multirow[t]{3}{*}{$* * r, q 0$} & $r \leqslant$, & $v,$. & rq,. & $r \Lambda, r$ & 19, & $v, \cdot$ & $r_{1}$, & $17, r$ & ـ - منففضة (اقلّلة من ع r درجة) \\
\hline & & & & $0 \leqslant, 1$ & & & & $r$ & 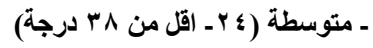 \\
\hline & & & & $v, v$ & & & & $r_{\cdot}, \varepsilon$ & - مرتفعة (^^ درجة فأكثر) \\
\hline \multirow[t]{3}{*}{ *Y, ฯ } & $r r, l$ & $v, q$ & $r v, q$ & $r r, \Lambda$ & $1 v, 7$ & $v, \uparrow$ & $r r, \varepsilon$ & $1 \leqslant, r$ & ـ ـ منخفضة العدالة: \\
\hline & & & & $\bullet \bullet, v$ & & & & $\varepsilon \leqslant, 9$ & ـ متوسطة ( ؟ ـ اقل من ^r درجة) \\
\hline & & & & 11,0 & & & & $\{, \Lambda$ & - مرتفعة (^^r درجة فأكثر) \\
\hline
\end{tabular}


Safaa R. A. N. El Saied and Marwa A. G. Ewes

\begin{tabular}{|c|c|c|c|c|c|c|c|c|c|}
\hline 1,90 & $r q, r$ & 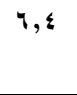 & $r r, v$ & $\bullet \vee, \xi$ & $r r, \cdot$ & $v, \cdot$ & $r v$, & $r q, v$ & ـ ـ منففضة (اقل من ع r درجة) \\
\hline & & & & $r q, r$ & & & & ov, l & ـ متوسطة ( ع ـ اقل من ^r درجة) \\
\hline & & & & $r, r$ & & & & 7,1 & ـ ـ مرتفعة (^^ درجة فأكثر) \\
\hline \multirow[t]{3}{*}{$* * \wedge, \wedge \uparrow$} & ץ & $7, \cdot 1$ & $r r, \varepsilon$ & $\Delta v, q$ & $1 \leqslant, 0$ & $\Lambda, \bullet$ & $r_{0,0}$ & Ir,r & ــ ــ المساءلةة: \\
\hline & & & & $r q, q$ & & & & $r \wedge, \Lambda$ & ـ متوسطة ( ع ـ اقل من ^r درجة) \\
\hline & & & & $r, r$ & & & & $\leq q$, & - مرتفعة (^^ درجة فأكثر) \\
\hline \multirow[t]{3}{*}{$* * 9, \leqslant \uparrow$} & Irr & iv,. & Ir^,. & $\varepsilon \cdot, r$ & $q r,$. & $i v, v$ & $10 \mathrm{~V}$ & Ir,r & ـ ـ الصحية: الكفة الكلية لحوكمة الوحدات \\
\hline & & & & $01,$. & & & & $\because 1, \mathrm{~V}$ & 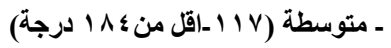 \\
\hline & & & & $\wedge, \wedge$ & & & & ץ , & ـ مرتفعة (ع ا ا درجة فأكثر) \\
\hline
\end{tabular}

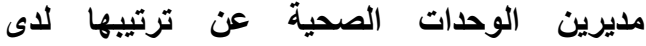
المستفيدين منها ليصبح ترتيبها عند المديرين كما لئها

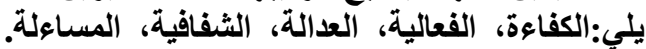

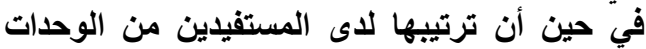

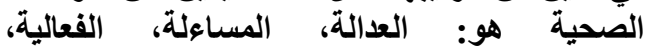

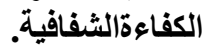

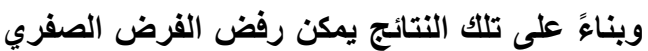

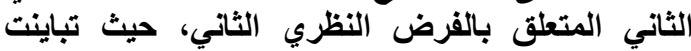
الأهمية النسبية لمبادئ الحوكمة الخمسة النمانية المدروسة

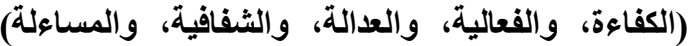

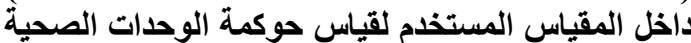

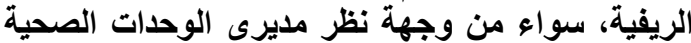

$$
\text { أو المستفيدين منها. }
$$

يتضح من النتائج السابقة أهمية كل مبلأ من مبادئ

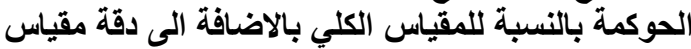

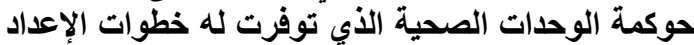

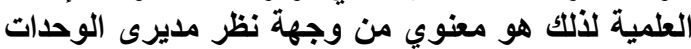
الصحية والمستفيدين منّها.

ومن النتائج ذات الأهمية أيضا هو اختلاف ترتيب الهيب أهمية مبادئ الحوكمة عند مديرى الوهية الوحدات الصحية عن الصني

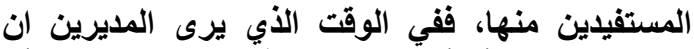

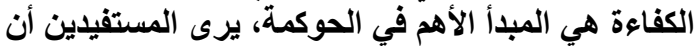

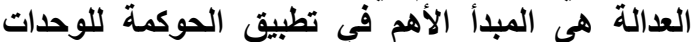

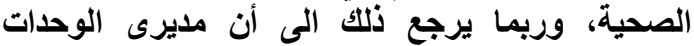

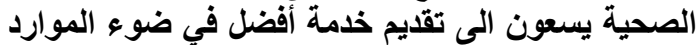

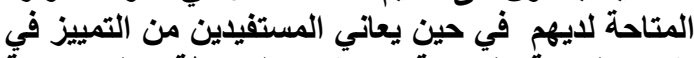

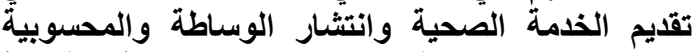
داخل الوحدات الصحية، ويتضح ذلك جليا في أهمية مبدأ

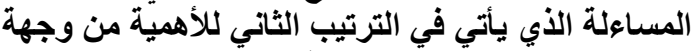

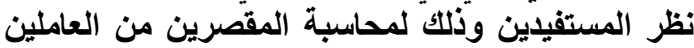
في الوحدات الصحية فهم يرون أنه إن لم يحاسب المقرين المقصر
ويتضح من النتائج الخاصة بحجم الفجوة وجود فجوة كبيرة بين درجة كل مبأ من مبادئ الحوكمة الفعلية

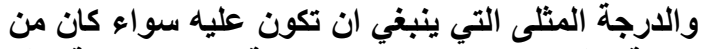

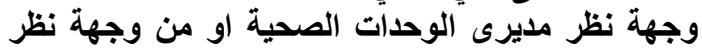

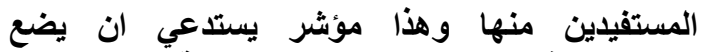

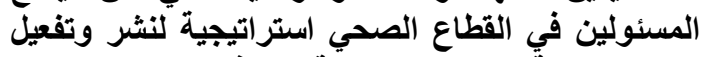

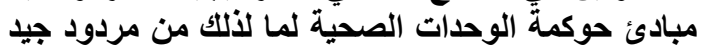
على مستوى الرعاية الصحية المقدم للمواطنين.

خامساً: النتائج الخاصة بتحديد الأهمية النسبية لكل مبدأ من المبادئ المستخدمة في قياس الأهية حوكمة الوحدات الصحية: Step- تم استخدام أسلوب تحليل الأنحار المرحلة Wise Multiple Regression Analysis الأهمية النسبية للمبادئ الخمسة المستخدمة في قياس

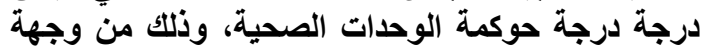
نظر كل من مديريى الوحدات الصحية وكذية ولك المستفيدين منها، حيث أوضحت مدير نتائج هذا التحليل والمعروضة المئية

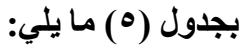
1- أن جميع المبادئ الفرعية المستخدمة في بناء

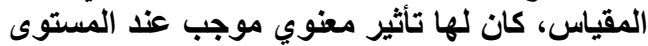

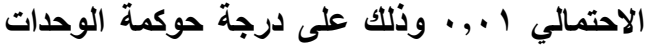

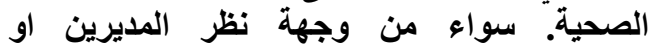
المستفيدين منها.

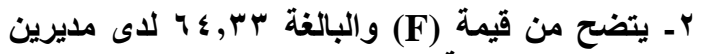

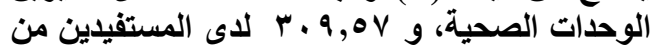

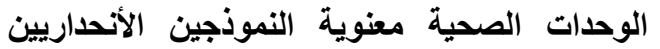
لعلاقة المبادئ الفرعية بلدرجة حوكمة الوحدات

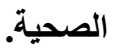
r- بالرجوع إلى قيم معامل الأندار الجزئي المعياري أظهرت النتائج اختلاف الأهمية النسبية للمبادئ المئي

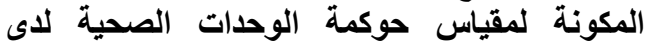


فلن يحدث أي تحسن في مستوى الرعاية الصحية المقدم

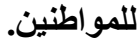

جدول (•): نتائج تحليل الأحدار المرحي لعلاقة المبادئ الفرعية لمقياس حوكمة الوحدات الصحية بالدرجة الكلية للمقياس.

\begin{tabular}{|c|c|c|c|c|c|c|c|}
\hline \multicolumn{4}{|c|}{ من وجهة نظر المستفيدين } & \multicolumn{4}{|c|}{ من وجهة نظر المديرين } \\
\hline قيمة (t) & الأنحدار الجزئي معامل & قايمة معامل & الفرعية الفئة & قيمة (t) & الأحدار الجزئي معامل & قيمة معامل الأنحدار & المبادئ الفرعية \\
\hline$* * 1,, 0$ & $\cdot, 710$ & 1,rr & 1 - العدالة & $* * \varepsilon, \wedge \varepsilon$ & $\cdot, 0 \wedge$ & 1,01 & 1- الكفاءة \\
\hline$* * q, r$. & $\cdot, \leqslant \leqslant 9$ & $\cdot, 99$ & r ـ المساعلة & $* * \varepsilon, 1\}$ & . & . , ^ & r ـ الفعالية \\
\hline$* * q, \vee \leqslant$ & $\cdot, r \wedge \varepsilon$ & ( & rـ الفعالية & $* * 4, r \mu$ &., 01 & 1,11 & بـ العدالة \\
\hline$* * 1 \leqslant, 7$ & . & $1, \cdot \varepsilon$ & ـ ــ الكفاءة & $* * \theta, \wedge$. & 每, & $\cdot, \wedge 0$ & ع ـ الثفافية \\
\hline$* * \mid r, r$ & . & 1, & هـ الشفافية & $* * \xi, \vee r$ & $\cdot, \varepsilon$. & $1, \cdot$ & هـ المساعلة \\
\hline
\end{tabular}

الصحي، انخفاض تكلفة تقديم الخدمة الصحية مقارنة بالقطاع الخاص، انتثار الامية والجهل لإى نسبة كبيرة

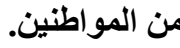

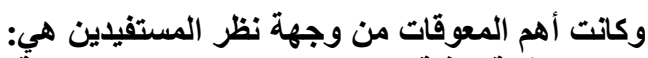

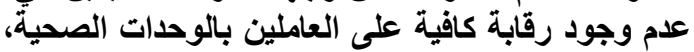

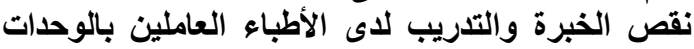

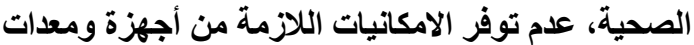

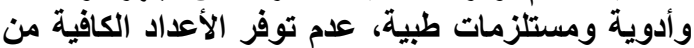
الأطباء خاصة في الامكان النائية، عدم معرفة الأبة المواطنين

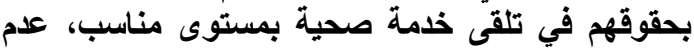

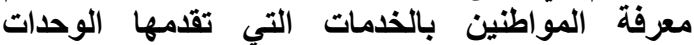
الصحية، تفضيل الأطباء العمل بالقطظع الخاص عن التراع

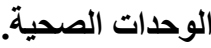

ساداً: التعرف على أهم معوقات تطبيق الحوكمة

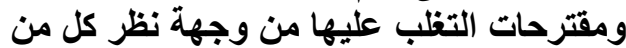

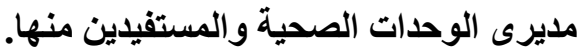

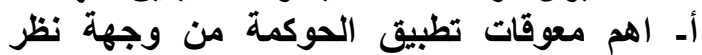
مديرى الوحدات الصحية والمستفيدين منها:

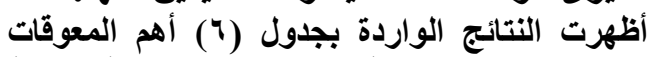
التي تواجه تطبيق الحوكمة في الوحدات الصحية الريفية التولية

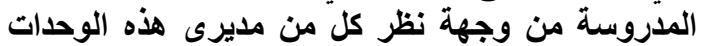

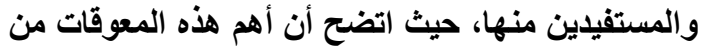

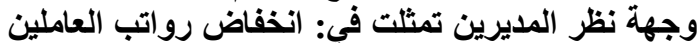

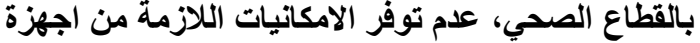

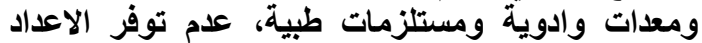
الكافية من الاطباء خاصة في الامكان النائية، عدام تدريب الأبي الاطباء على الاساليب الادارية الحديثة، عدام توفر الألوعي الكافي بمبادئ الحوكمة لاى غالبية العاملين بالقطاع

جدول (؟): أهم معوقات تطبيق الحوكمة من وجهة نظر مديرى الوحدات الصحية والمستفيدين منها منيا

\begin{tabular}{|c|c|c|c|c|c|}
\hline \multicolumn{3}{|r|}{ من وجهة نظر المستفيدين } & \multicolumn{3}{|r|}{ من وجهة نظر المديرين } \\
\hline$\%$ & 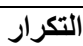 & معوقات تطبيق الحوكمة & $\%$ & 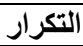 & معوقات تطبيق الحوكمة \\
\hline $9 \leq$, & IVY & - علام وجود رقابة كافية على العاملين & $\Lambda \vee, \vee$ & $\varepsilon r$ & ـ انخفاض رواتب العاملين بالقطاع الصحي. \\
\hline $91, r$ & $17 \mathrm{~V}$ & - نقص العبلين بالوحدات والصحية. لدى الاطباء & 11,7 & $\varepsilon$. & - عدمات توفر الامكانيات اللازمة من و اجهزة \\
\hline$\wedge \leqslant, 1$ & $10 \leqslant$ & - عدم توفر الامكاتيات اللازمة من ومسية أجهزة & $v 9,0$ & rq & - علم توكان الأعداد الكافية من الاطباء خاصة \\
\hline
\end{tabular}


Safaa R. A. N. El Saied and Marwa A. G. Ewes

\begin{tabular}{|c|c|c|c|c|c|}
\hline$V \vee, \uparrow$ & $1 \leqslant r$ & - علدم توفر الأعداد الكافية من الاطباء في & $v^{r}, 0$ & rq & - علدم تدريب الأطباء على الأساليب الادارية \\
\hline$T V, Y$ & Irr & - عدمة معرفة المواطنين بحقوقهم في تلقى مناسب. & $v_{r}, 0$ & rq & - لدى غالبية العاملين بالقطي باع الصدئ الحوكمة. \\
\hline ०V, ६ & 1.0 & - تلدم معرفة الوحدات الصواطينة. بالخدمات التي & $71, r$ & $r$. & - مقارنة باضقطاع الخاصة تقاضم الخدمة الصحية \\
\hline $0 \leqslant, 7$ & $1 \ldots$ & - سلو اطنين وعاملة العاملين بالوحدام بهات الصحية & 00,1 & YV & ـ المواطنتين. الامية والجهل لاى نسبة كبيرة من \\
\hline
\end{tabular}

على نثر الوعي لاى المواطنين بدورهم في تطبيق مبادئ الحوكمة في الوحدات الصحية.

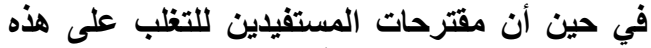

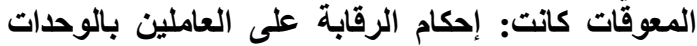

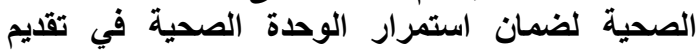

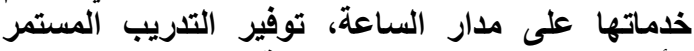

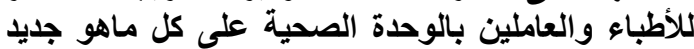

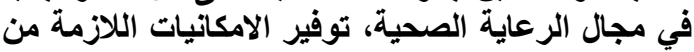

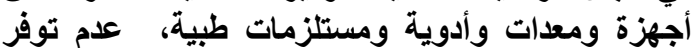

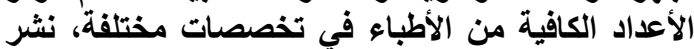
الوعي الكافي لاى المواطنين لمعرفة حقوقهم في مجال

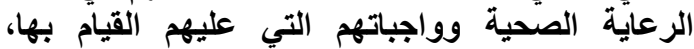

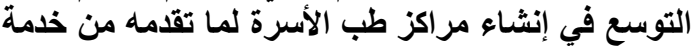

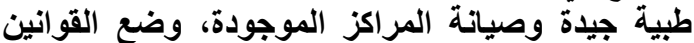
التي تمنع الجمع بين العمل في القطاع الصحي الحكومي

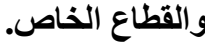

ب- مقترحات التظلب على معوقات تطبيق الحوكمة من وجهة نظر كل من مديرى الوحدات الصحية

$$
\text { والمستفيدين منها: }
$$

أظهرت نتائج الدراسة الواردة بجدول (V) أن أهم أهمات

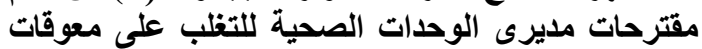

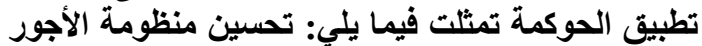

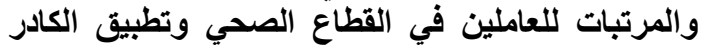

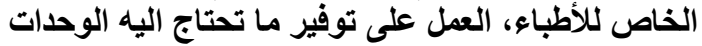

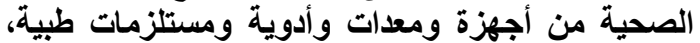
زيادة عدد الأطباء العاملين في الوحدات الوات الصحية خاصة الصات

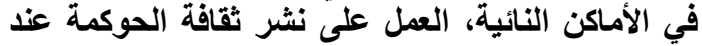

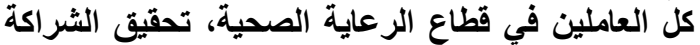

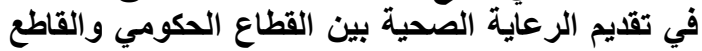

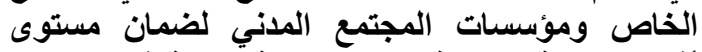
أفضل للذدمة الصحية، تقديم الخدمة ألطبية في الوحدات الفئ

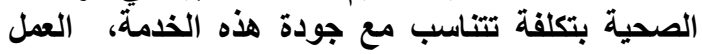

جدول (V)): مقترحات التظلب على معوقات تطبيق الحوكمة من وجهة نظر مديرين الوحدات الصحية والمستفيدين منها

\begin{tabular}{|c|c|c|c|c|c|}
\hline \multicolumn{3}{|r|}{ من وجهة نظر المستفيدين } & \multicolumn{3}{|r|}{ من من وجهة نظر المديرين } \\
\hline$\%$ & 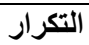 & أهم المقترحات & $\%$ & 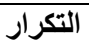 & أهم المقترحات \\
\hline $9 \uparrow, \Lambda$ & iv. & 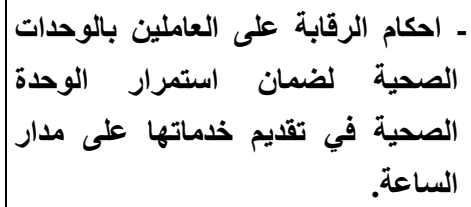 & $\Lambda \mu, V$ & \&1 & 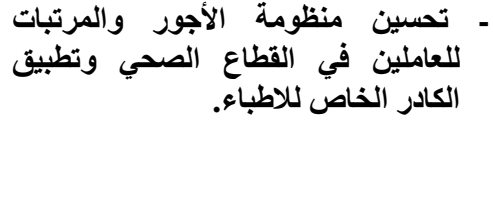 \\
\hline $91, Y$ & $19 \mathrm{~V}$ & 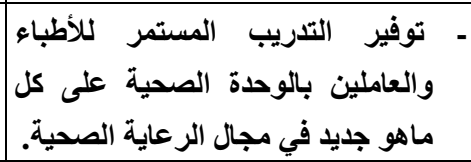 & 11,7 & \&. & 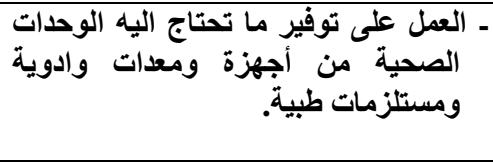 \\
\hline$\overline{\Lambda \uparrow, .}$ & 10. & - توفدات وأدوانية ومستلزممات طبية. & $v 1, \varepsilon$ & ro & 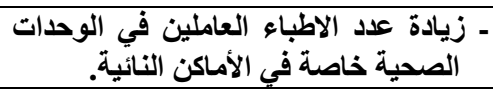 \\
\hline$V \varepsilon, \Gamma$ & 147 & - توفصرات مختلفة. الأعية من الاطباء في & $10, r$ & rr & 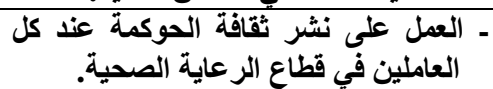 \\
\hline 10,7 & Tr. & 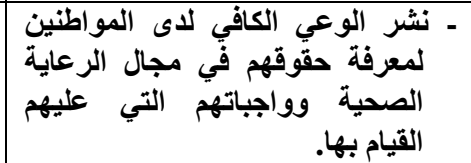 & $70, r$ & rY & 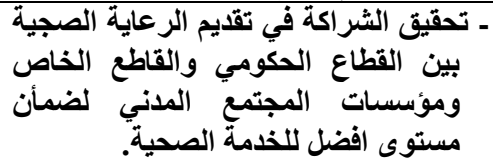 \\
\hline $7, r$ & $11 Y$ & 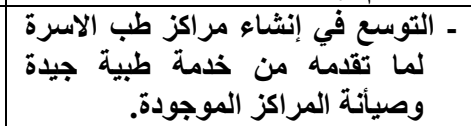 & $71, r$ & $r$. & 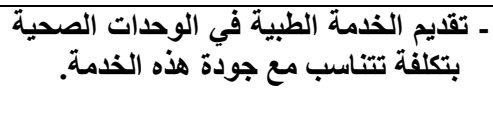 \\
\hline $07, \Lambda$ & $1 \cdot \varepsilon$ & 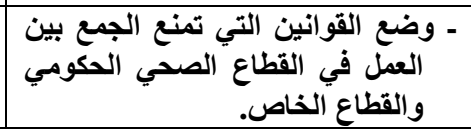 & 00,1 & YV & - العمل على في نثر الوعيق مبادئ لائ الحوكمة فينين \\
\hline
\end{tabular}




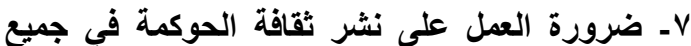

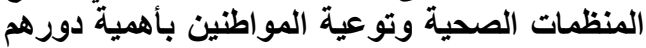

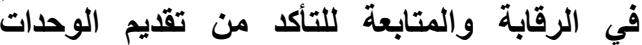
الصحية الريفية لخدمة صحية متميزة.

$$
\text { المراجع باللغة العربية }
$$

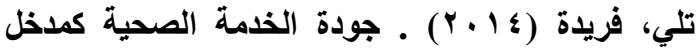

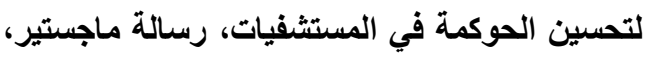
كلية العلوم الاقتصادية والتجارية والادارية، جامعة فلئة بسكرة، الجزائر.

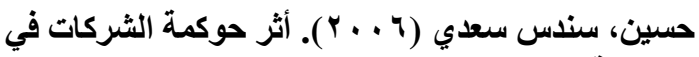

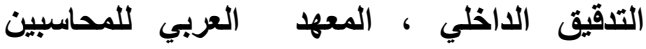

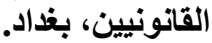

حنتر، مصطفى، هاني ابو الفتوح، عبد الله الكريمي،

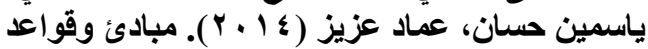
الحوكمة بالمستثفيات، جمعية الحوكمة والثفافية المافية في قطاع الصحة، القاهرة، مصر.

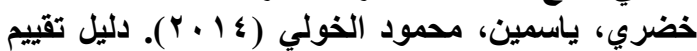
الحوكمة الرشيدة في القطاعات الخدمية، مركز العقد

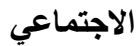
محمد، اشرف يونس، مازن محمد محمود بركات

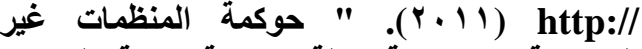
الحكومية " دراسة حالة بجمعية تنمية المجتمع بـئية

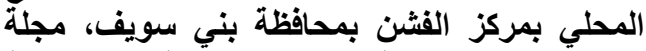

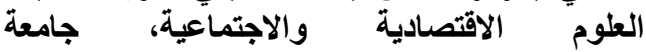

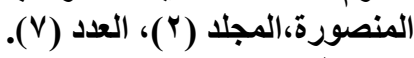

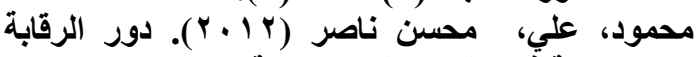
الداخلية في تطبيق نظام الحوكمة، سوريا.

مركز المعلومأت ودعم اتخاذ القرار بمحافظة الفيوم.

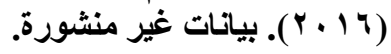

$$
\text { المراجع باللغة الانجليزية }
$$

Freeland, C. (2007). Basel Committee Guidance on Corporate Governance for Banks, paper presented to: Coorporate Governance and Reform: Paving the Way to Financial Stability and Development, a conference organized by the Egyptian Banking Institute, Cairo, May 7 - 8.
التوصيات

أ- توصيات متعلقة بإعداد مقياس كمي لحوكمة

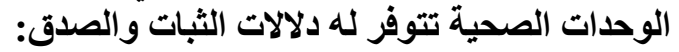

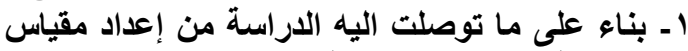

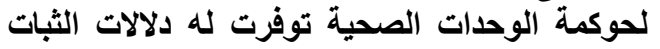

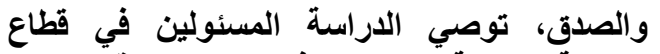
الرعاية الصحية باستخدم هذا المقياس للوقوف فئف على فئي

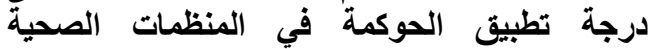
المختلفة، وذلك للنهوض بمستتوى الرعاية الصحية

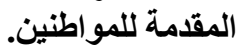

r - توصي الدراسة أيضا باجر اء مزيد من البحوث لتطوير لتوير

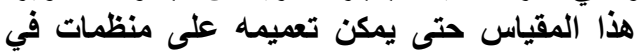
قطاعات اخرى ولا يقتصر تطبيقة على المنظمات فئل فئل الصحية فقط.

بـ توصيات متعلقة بلرجة تطبيق الحوكمة بمبادئها المختلفة:

rـ بناء على ما توصلت اليه الدراسة من وجود فجوة بين

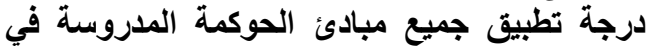

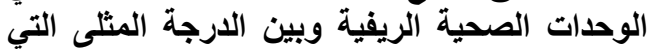

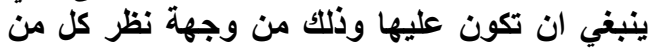

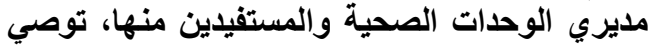
الاراسة المسئولين عن القطاع الصحي بأهمية إزالة

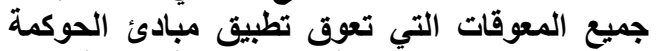
وتوفير الامكانيات التلازمة لتقديم خدمة تبليق صحية جيدة كافة المو اطنين دون تمييز. عـ توصي الاراسة كذلك الوحدات الصحية بضرورة

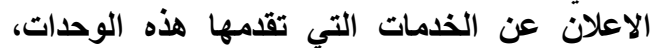

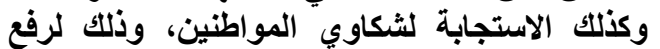
درجة رضا المواطنين عن الخدمات التي تقدمها.

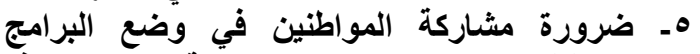
والخطط التي تتبناها الوحدات الصحية حتى التئ تلبي هذه التهات البرامج و الخطط الاحتياجات الفعلية للمواطنين.

ج- التوصيات الخاصة بمعوقات تطبيق الحوكمة في الوحدات الصحية: آ- بناء على ما توصلت اليه الدراسة من التعرف على منى

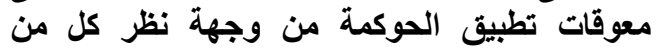

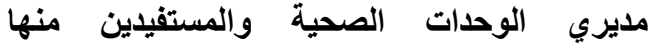
ومقترحات التظلب عليها، توصي الدراسة المسئولين في القطاع الصحي محاولة أزالة هذه الثئ المعوقات

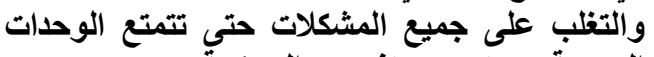
الصحية بمستوى مرتفع من الحوكمة. 


\title{
GOVERNANCE OF RURAL HEALTH UNITS IN FAYOUM GOVERNORATE
}

\author{
Safaa R. A. N. El Saied and Marwa A. G. Ewes \\ Agricultural Economics Dept., Fac. Of Agric., El- Fayoum Univ.
}

\begin{abstract}
This study aimed basically to achieving the following objectives: developing a quantitative, valid and reliable scale of the governance of rural health units, describing the degree governance by its different principles in the studied health units, identify the significance of the difference between the average degree the principles of governance of health units studied (from the point of view of both health unit managers and beneficiaries), measure the size of the gap between the real degree of governance in rural health units and the degree to which they should be, and finally to identify the barriers of the application of the governance and methods to overcome it in the studied health units.

Data were collected from 49 health units managers in Fayoum, Etsa and Youssef El Siddiq districts in Fayoum governorate. Beneficiary data were collected from 183 heads of households from the previous three districts. The data were analyzed using a number of statistical analysis methods. Spearman Brown, The split-half method, Guttman and Cronback methods to estimate the reliability coefficient of the governance of rural health units scale., as well as the use of the $t /$ test and Step-Wise Multiple Regression Analysis.

The most important results were that the stability coefficients of the governance of health units' standard and its sub-principles were all relatively high, providing a great deal of confidence in using this measure. In the view of $(61.7 \%)$ of the managers, the degree of implementation of the overall governance within the health units is medium and for the overall degree of governance of the rural health units, while this percentage dropped to (51\%) among the beneficiaries of the rural health units. The gap between the degree of governance of health units has reached the optimum level (93 degrees) from the point of view of managers while the gap has increased to (122) from the point of view of beneficiaries. The value of (F) of 64.33 in health unit managers and 309.57 in beneficiaries of health units is significant in the two models of the relationship of subprinciples to the degree of governance of health units.
\end{abstract}

Key words: Governance- rural health units- Transparency- Accountability

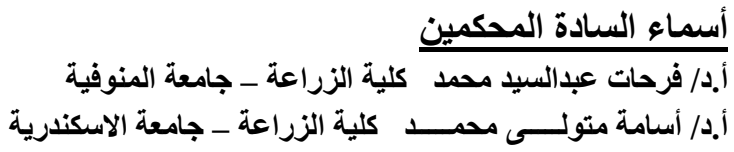

